\title{
Study on the Enterprise Strategic Reform Driving Power and Methods
}

\author{
Yanfa Chen
}

\author{
NanChang Institute of Science \& Technology, Nanchang,330108
}

\author{
Keywords: Strategic Transformation; Stimulus; Barriers
}

\begin{abstract}
Strategic transformation is the challenge that enterprise is facing today and enterprises should carry out deep reform in the turbulent environment both internally and externally. However, there is no monograph or books systematically talking about strategic transformation. This paper is going to analyze different reasons of strategic transformation nowadays and to prove that it is a tough problem that enterprises have to in terms of economic globalization, network informationization and industrial structure adjustment etc. In addition, it clears that strategic transformation can be deemed as profound reform relating all perspectives of enterprises; it also suggests that key models which will determine the result of transformation. These key factors can be divided into strategy, leadership, business process management, continuous improvement, etc., which can also be subdivided into sharing targets, transformation based on core competencies, appropriate transition time, strong leadership to launch a wide range of staff participation, new corporate culture shaping, key process of improvement, new strategic performance appraisal systems short-term results, and institutionalization etc.
\end{abstract}

\section{Introduction}

Strategic reform plays a pivotal role in making an enterprise stronger. Since late 1980s, the theory of strategic reform had been gradually formed in the business administration of Europe and the United States. So far, lots of researches studying on corporate strategy and its influencing factors have been carried out from different perspectives. After entering the 21 st century, this theory has been developed a lot. However, researches are only focused on strategic reform mode and how to organize and lead, which do not reveal the problems by integrating the reform process and influential factors. So, the problem is that we are in shortage of practical guidance while a glittering array of managers cannot predict the complexity. As a result, it will definitely be out of control during the reform process. This paper is going to combine the reform process and influential factors to help enterprises recognize both the stimulus and barriers from the perspectives of theory and practice, which will be helpful. This is a new research field, and can be considered as an initial study based on limited contents and research skills.

\section{Concept of Strategic Reform}

Generally speaking, strategic reform is to help enterprises dynamically coordinate the internal environment and objective environment so as to make enterprises very competitive. Strategic reform theory appeared in the late 1980s in the business administration field of European countries and United States, which has been constantly innovated. However, there are few representative literatures clearing the concept of this theory and the definition of strategic reform is vague while there are even less definitions for enterprise strategic reform.

Strategic reform is a systematic system process to launch implement and constantly reform by combining organization elements based on the dynamic coordination principle among environment, strategy and organization, aiming to help enterprises obtain sustainable competence, which mainly observes the circumstances, predicts the future and comes up with supportive opinions according to both internal environment and external environment. Judging from this concept, we can see the unitized structural characteristics covering strategic reform targets, incentives, principles as well as the contents and process. 


\section{Main Influential Factors for Strategic Reform}

In each phases of strategic reform process, there are relative influential factors. In the first stage, there are factors which stimulated the requirement of strategic reform; in the implementation stage, there are stimulus and barriers; in the feedback period, there are reflects etc. Enterprise strategic reform is not established based on groundless rumor but is carried out based on certain time. Different enterprises have their own strategic reform reasons and some are internal reasons while some are external causes, showing in fig. 1:

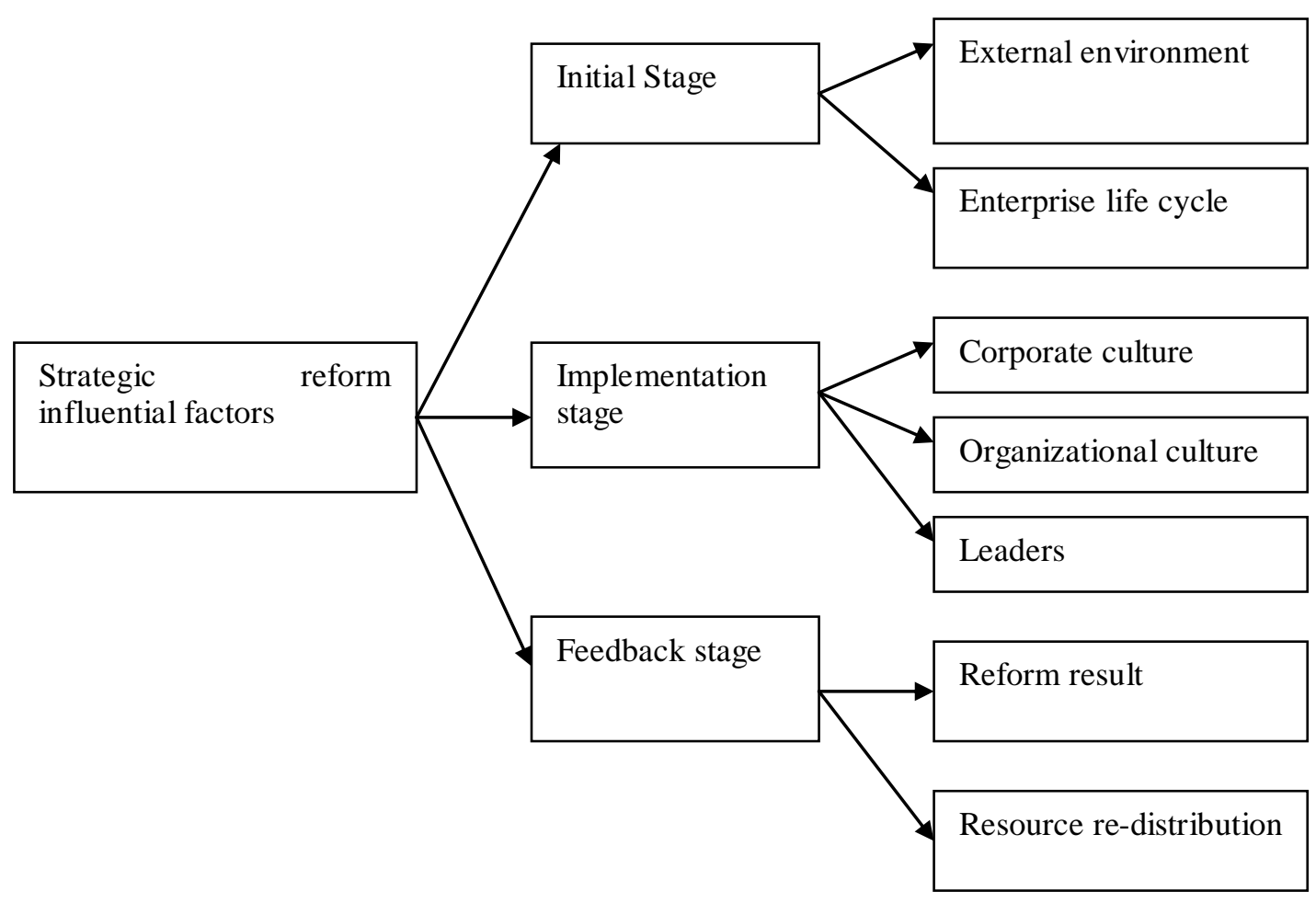

Figure 1. Main influential factors for strategic reform

All enterprises exist in certain environments and the environment changes will inevitably make relevant changes on the organizational structure, which will further affect the strategies. For example, the industrial structure adjustment: the development of science and technology contributes to the reform of products and technological process and at the same time aggravates the changes and competition in both domestic market and international market. Environment is made up of diverse sub-environment with similar factors, including market sub-environment, economy sub-environment, politics sub-environment, technology sub-environment, industry sub-environment and international market sub-environment etc. The effect on organizational structure caused by environment mainly shows in the following three levels:

To begin with, the effect on job and department design. Organization is the sub-system of social economy and the social work distribution determines different duties for different departments. Hence, the job and departments setting will be different.

Secondly, effect on different departments. In different environments, different departments should contribute more or less efforts to finishing a task, which affects the targets realization.

The advance of te Thirdly, effect on the overall characteristics of organizational structure: there are different requirements on organizational structure based on external environment stability. If the external environment is stable, the positive organizational structure will guarantee the normal operation of a corporate; or we have to design a flexible organizational structure so as to deal with the changing external environment.

chnology, especially the application of new technology such as internet technology has a tremendous influence on traditional enterprises: 
Judging from a macro perspective, the economic system, scheme change, rapid development of internet all urge us to finish the change from planned economy to market economy. Therefore, there is only one way out for traditional enterprises when challenged by internet. That is to adjust the current management and operation system, introduce themselves to the internet economy and take advantage of multiplication effect of internet to be the winner of information economy era. Based on the information technology development, the service objectives can be expanded to various fields by catalyzing the industrial structure adjustment: information transferring internet, finance information internet, commerce information internet, technology information internet, government information trade, which can make the information service diversified. Therefore, we can conclude that the increase of information industry in GDP will contribute to the change of industrial structure. Through the internet, enterprises will be able to shorten the management process and decrease the management price by decreasing the cost and enhancing the competence.

\section{Strategic Reform Methods for Enterprises}

Clear the reform target. We have to confirm that we cannot carry out reform blindly. The strategic reform is suggested because the originally fixed strategy cannot be adapted to the new situation and environment and enterprises have to survive based on changes. For the strategic reform being implemented, the target should be firstly cleared.

Have a positive understanding of barriers. The strategic reform will inevitably bring about various barriers, which are subsidiaries of reform and no enterprise an avoid it. However, successful enterprises will be able to weaken the barriers and fully play the positive factors to finally realize the strategic reform.

Flexible organizational structure: the communication barriers, benefits barriers are all cau sed by organizational structures. Chinese enterprises should reduce the dominant control and power because only in this way, can we reduce the communication misunderstanding and help all employees to clear the target, meaning and implementation process of strategic reform. A healthy and excellent organization should be at least an organization that is able to maintain the internal balance. So-called balance is about the balance of the whole system, including the balance in terms of cultural systems, strategy, people, organization, system and culture etc.

Innovate culture. While facing inertial barriers, Chinese enterprises should take the initiative to introduce advanced cultural philosophy and cultivate learning enterprises. Only in this way, can we cultivate core philosophies including encouragement and passion for enterprises. To implement this series of philosophies, systems and culture, we can regulate the behaviors, including making the strategic reform consistent with concrete policies and actions as well as employee's behaviors. Only by employing and cultivating employees who adhere to the philosophies, can we encourage them to work on the target.

\section{Conclusion}

While facing the fierce competition, Chinese enterprises should keep a learning attitude and become alert toward the environment changes. In addition, they should positively clear the importance of strategic reform and improve the connotation of philosophies. What's more, they should refer to the successful cases of foreign companies and gain valuable experience from them. By taking advantage of correct theories, those enterprises should fully play the advantages of organization culture, organizational structure and leaders to weaken the factors of barriers so as to successfully implement the strategic reform. This paper divides the influential factors of strategic reform into fixed barriers and key elements. The corporate culture, organizational culture and the personal quality of leaders are key factors influencing whether the strategic reform will be successful or not; fixed barriers, inertial barriers, benefits barriers, communication barriers, philosophy barriers are fixed elements hindering the process of strategic reform. Successful enterprises are able to apply innovated enterprise culture, flexible organizational structure, and outstanding cultures to weaken the barriers so as to promote the successful implementation of strategic reform. 


\section{References}

[1]. Homocianu D. The Information Resource Management in a Virtual Enterprise[J]. Social Science Electronic Publishing, 2014:pp.180-192.

[2]. Carter K B, Farmer D, Siegel C. Actionable Intelligence: A Guide to Delivering Business Results with Big Data Fast![J]. 2014.

[3]. Angko W. Analysis of the Performance of Export Processing Zones in Ghana[J]. Journal of Business Administration \& Education, 2014, 5(1).

[4]. Mccormack T, D'Arcy P, French J. SYSTEM AND METHOD FOR ROUTING WORK REQUESTS IN AN ENTERPRISE:, US 20150365342 A1[P]. 2015.

[5]. Hendrikse G,Hippmann P, Windsperger J. Trust, transaction costs and contractual incompleteness in franchising[J]. Small Business Economics, 2015, 44(4):867-888.

[6]. Huang J W, Li Y H. Green Innovation and Performance: The View of Organizational Capability and Social Reciprocity[J]. Journal of Business Ethics, 2015:1-16.

[7]. Boddie W S, Kun L. Global food safety product management: a holistic, integrated, strategic approach ( proposed )[J]. Health and Technology, 2014, 4(2):135-143.

[8]. Kabra G, Ramesh A. Analyzing ICT Issues in Humanitarian Supply Chain Management: A SAP-LAP Linkages Framework[J]. Global Journal of Flexible Systems Management, 2015, 16(2):157-171.

[9]. Alfred W U, Dula C. The Senior Citizen Home Safety Association: Enabling Active, Ageing-in-Place in Hong Kong[J]. 2014.

[10]. Iacob M E, Kroon H, Quartel D A C. Executable enterprise architecture models : enabling business analytics using the Monte Carlo method[J]. 2014.

[11]. LAN Xian XU Xiao long Impro China Limited School of Business Administration, Universi S F. A Study of Effective Formation of Enterprise Quality Management System[J]. Science Economy Society, 2014.

[12]. Oh H, Bae J, Kim S J. Can Sinful Firms Benefit from Advertising Their CSR Efforts? Adverse Effect of Advertising Sinful Firms' CSR Engagements on Firm Performance[J]. Journal of Business Ethics, 2016:1-21. 